\title{
Indirect Spectrophotometric Determination of Diclofenac and Isoxsuprine Drugs Using N-bromosuccinimide and Malachite Green Dye
}

\author{
Leena A.S.M. Al-Salim \\ Marwan M. Al- Sharook \\ University of Mosul / College of Education For pure Sciences \\ Department of Chemistry \\ Leena.adi1484@uomosul.edu.iq \\ DOI: 10.33899/edusj.1999.163311 \\ Marwan.sh53@uomosul.edu.iq \\ Received \\ Accepted \\ 28/ 08 / 2018 \\ $03 / 10 / 2018$

\begin{abstract}
Simple, accurate and sensitive indirect spectrophotometric method for assay of diclofenac (Di) and Isoxsuprine (IS) in pure and pharmaceutical formulation has been developed. The method is based on oxidation of (Di) and (IS) by $\mathrm{N}$ bromosuccinimide in acidic medium. The excess of oxidant is determine by reaction with malachite green dye and the absorbance is measured at $615 \mathrm{~nm}$. Under the optimized experimental conditions, Beer's law is obeyed in concentration range 0.5$18,1-18 \mu \mathrm{g} / \mathrm{ml}$ with molar absorptivity $5.1 \times 10^{4}$ and $4.6 \times 10^{4} \mathrm{~L} \cdot \mathrm{mol}^{-1} \cdot \mathrm{cm}^{-1}$ for (Di) and (IS) respectively. The limits of detection (LOD) $0.0314,0.038$ and quantification are $0.0104,0.126 \mu \mathrm{g} / \mathrm{ml}$. with the accuracy (average recovery) $100.80 \%, 101.20 \%$ for above drugs respectively and the precision (RSD) less than $1.5 \%$ for both drugs. The proposed method is applied successfully for assay of pharmaceutical formulations.
\end{abstract}

Key words: Diclofenac, Isoxsuprine, Malachite green, spectrophotometry 
التقدير الطيفي غير المباشر للدايكلوفيناك والأيزوكسبرين بصورتهما النقية ومستحضراتهما الصيد لانية باستخدام N - بروموسكسينمايد وصبغة أخضر الملاكيت

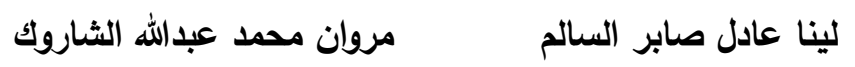

جامعة الموصل / كلية التربية للعلوم الصرفة

$$
\text { قسم الكيمياء }
$$

Leena.adil484@uomosul.edu.iq DOI: 10.33899/edusj.1999.163311

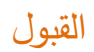 \\ الاستلام \\ $2018 / 10 / 03$ \\ $2018 / 08 / 28$
}

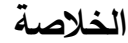

تم تطوير طريقة طيفية بسيطة وسريعة وحساسة لتقدير كلا من الدايكلوفيناك والأيزوكسبرين في صورتهما

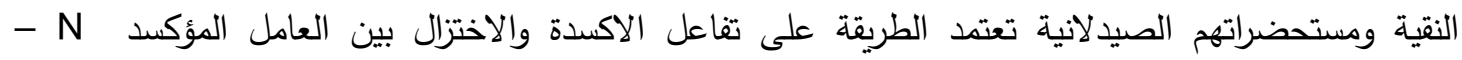

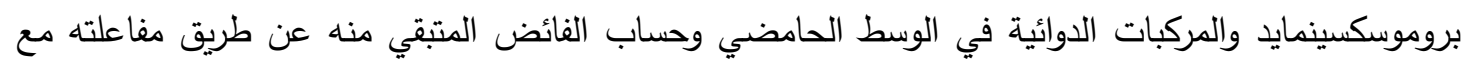
صبغة أخضر الملاكيت حيث يؤدي الى اكسدة الصبغة وقصر لونها كميا وقياسها عند 615 نانوميتر • وان حدود تطبيق قانون بير ضمن مديات التراكيز 0.5-1,18-18 مايكروغرام / مللتر لكلا الدوائين وبامتصاصية

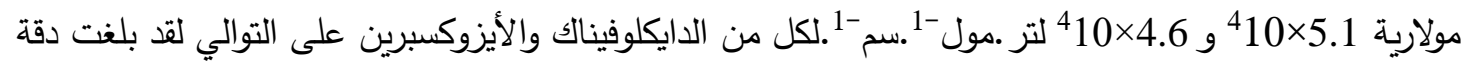

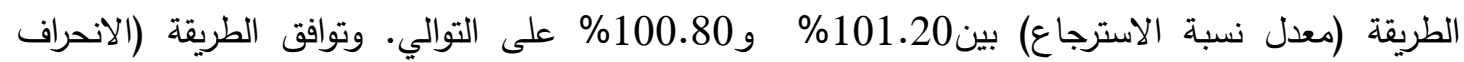
القياسي النسبي) أقل من 1.5\% لكلا الدوائيين وتم تطبيق الطريقة بنجاح في تقدير الدايكلوفيناك والأيزوكسبرين في المستحضرات الصيدلانية . الكلمات المفتاحية: الدايكلوفيناك والأيزوكسبرين واخضر الملاكيت والمطياف الفوتومتري 


\section{المقدمة}

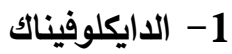

عبارة عن مادة صيدلانية مصنفة ضمن مضادات الالتهابات اللاستيرودية وهو منتثر في الصيدليات حول

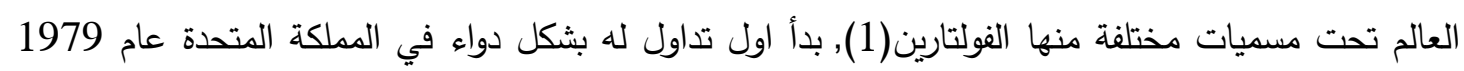

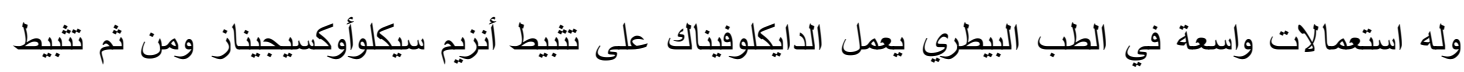

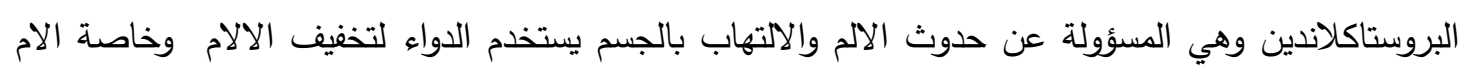

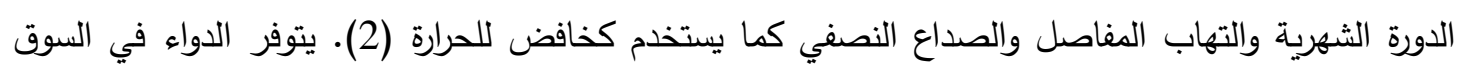

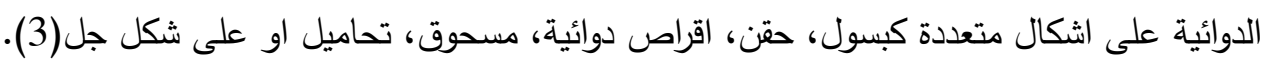

يمتلك الدايكلوفيناك الصيغة الكيميائية التالية

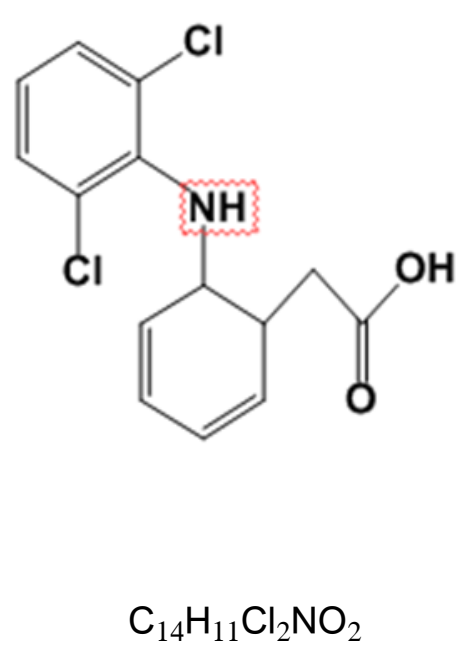

M.wt $=296.148 \mathrm{~g} / \mathrm{mole}$

2- 2 الأيزوكسبرين هيدروكلوريد

وهو عبارة عن دواء فعال يستخدم لتوسيع الاوعية الدموية(4) إذ يعمل على ارخاء اوردة العضلات الملساء

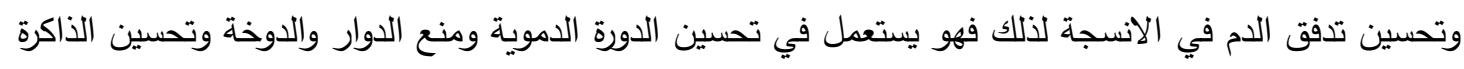

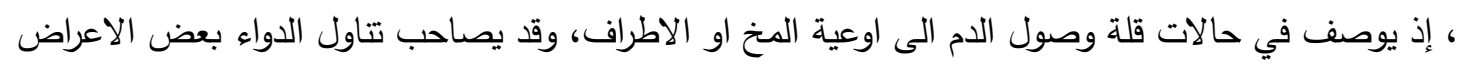

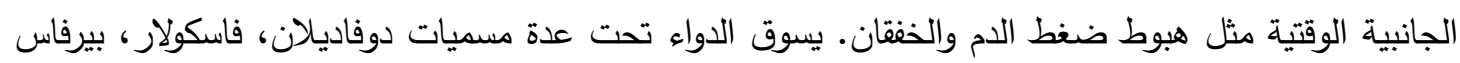
تحتوي جميعها على المادة الفعالة ايزوكسبرين(5). 
يمتلك الايزوكسبرين هيدروكلوريد الصيغة الكيميائية التالية(6):<smiles>CC(NCCOc1ccccc1)C(O)c1ccc(O)cc1</smiles>

$\mathrm{C}_{18} \mathrm{H}_{24} \mathrm{CINO}_{3}$

$M \cdot w t=301.39$

استخدمت تقنيات تحليلية متعددة لتقدير الدايكلوفيناك تضمنت كروماتوغرافيا السائل عالي الاداء(7-10) ، وكائل والفولتامتري الموجة المربعة(11)، وكروماتوغرافيا الغاز_طيف الكتلة(12)، وتكوين معقدات الثحنة المنتقلة(13-15)، تم وصف طريقة طيفية تعتمد على مفاعلة الدواء مع كلوريد الحديد الثلاثي ليعطي الحديد

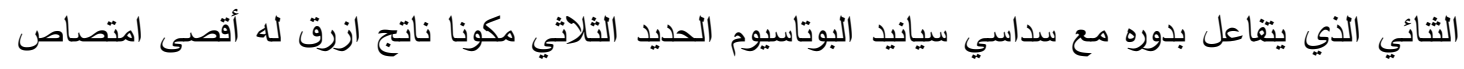

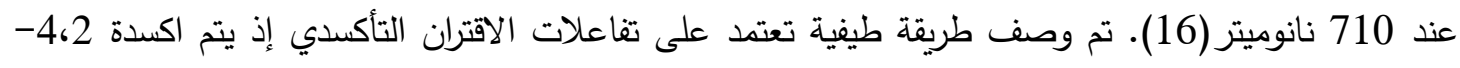

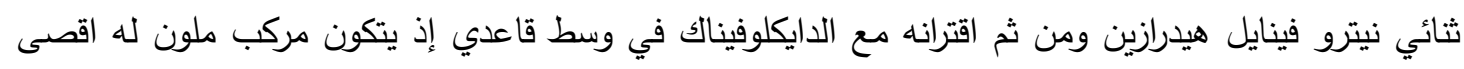
امتصاص عند 600 نانوميتر (17). تم تطوير طريقة طيفية وذلك بمفاعلته مع عنصر النحاس الثنائي إذ يتكون معقد اخضر بين النحاس والدايكلوفيناك له اقصى امتصاص عند 680 نانوميتر في وسط محلول منظم متكون من حامض الخليك وخلات الصوديوم دالته الحامضية تساوي 3.5 ويتم استخلاص المعقد بوساطة فئس الكلوروفورم(18).تم وصف طريقة طيفية تعتمد على تفاعل كاشف 1،2- نفثوكينونون-4- سلفونات (NQS)

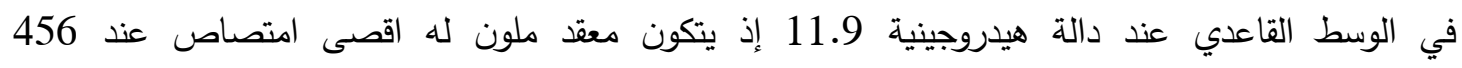

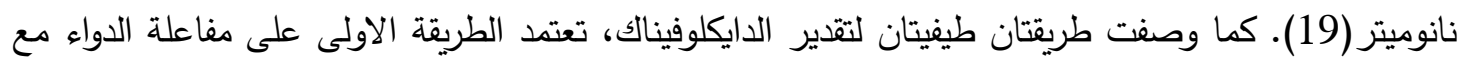

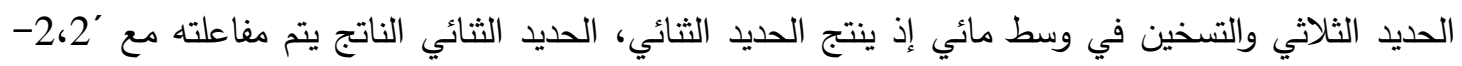
ثنائي بريدين (bipyridine - - 2',2) له اقصى امتصاص عند 520 نانوميتر ، وفي الطريقة الثانية تتم معاملة الدايكلوفيناك مع صبغة المثيل الازرق في وسط الفوسفات المنظم دالته الحامضية 6.8 لتكوين معقد يتم استخلاصه بوساطة الكلوروفورم والذي له اقصى امتصاص عند 640 نانوميتر (20). واستخدمت طريقة فلورومترية وذلك بمفاعلة الدواء مع ايون السيريوم في وسط حامضي(21). تم تطوير طريقة طيفية تعتمد على ولى

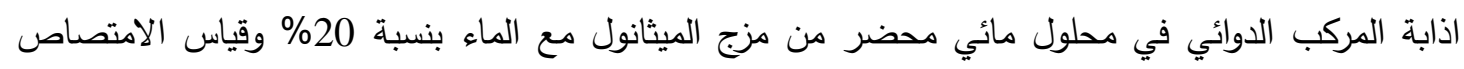
عند 277.5 نانوميتر (22). تم وصف طريقة طيفية لونية تعتمد على تفاعلات الأزوتة والاقتران إذ يتم ازوتة المركب 4-كاربوكسي-26- ثنائي نيترو بنزين ايون الدايزونيوم ومن ثم اقترانه مع الدايكلوفيناك. إذ يتكون معقد الدايزونيوم والذي له اقصى امتصاص عند 470 ن نانوميتر (23). وصفت طريقتان الاولى تسحيحية والاخرى طيفية تعتمد الطريقة الاولى على اذابة المركب الدوائي في حامض الخليك الثلجي بعدها يتم التسحيح 
مع 0.1 مولاري حامض البيركلوريك بوجود دليل البلورة البنفسجية (crystal violet) وتلتلخص الطريقة الثانية بإذابة المستحضر الدوائي في محلول من 0.1 مولاري هيدروكسيد الصوديوم والميثانول بنسبة (7:3 ) وقياس الامتصاص عند 296 نانوميتر (24) موله

كما استخدمت تقنيات تحليلية متعددة ايضا لتقدير الايزوكسبرين مثل الحقن الجرياني (25) وطيف الاشعة

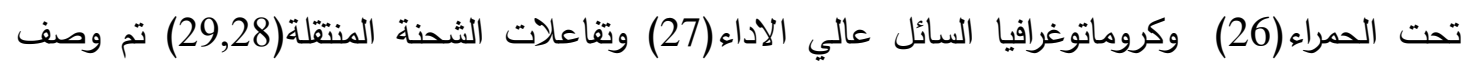
طريقتان فلورومتريتين لتقدير الايزوكسبرين تعتمد الطريقة الاولى على قياس الفلورة للدواء مباشرة عند طول موجة

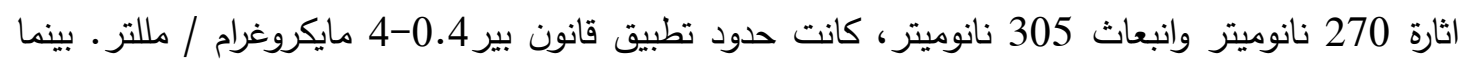

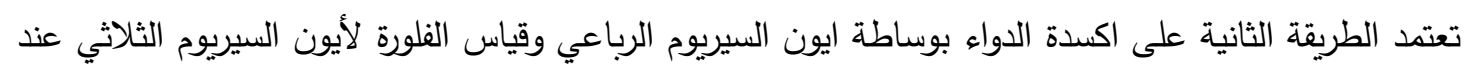
طول موجة اثارة 253 نانوميتر وانبعاث 355 نانوميتر (30). تم وصف طريقة طيفية تعتمد على قياس الندئ الناتج

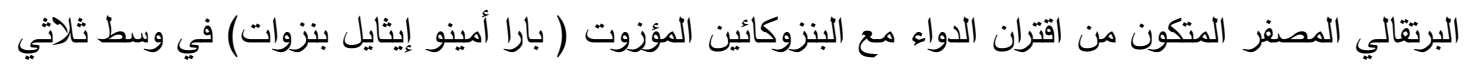

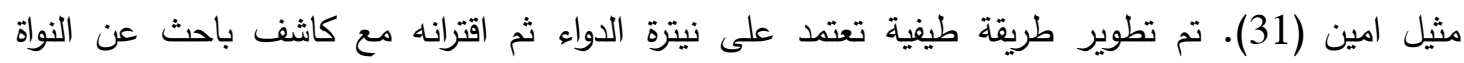

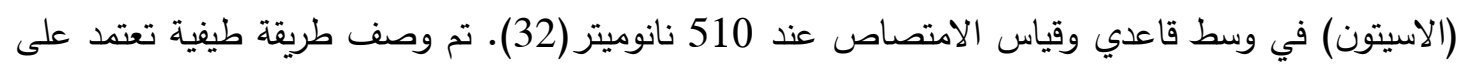
اكسدة الدواء بوساطة الكلورامين T في وسط حامضي وحساب الفائض من العامل المؤكسد مع الايوديد وقياس الامتصاص عند 590 نانوميتر (33). تم وصف طريقة طيفية لتقدير الايزوكسبرين في الاقراص الدوائية والادرار

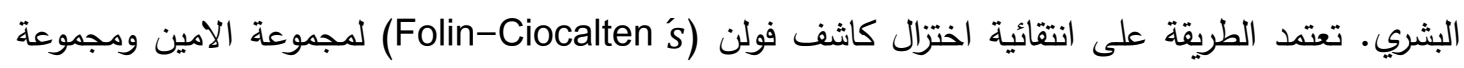
الفينول الموجودة في الدواء في وسط قاعدي لتكوين محلول ملون له اقصى امتصاص عند 770 نانوميتر (34).

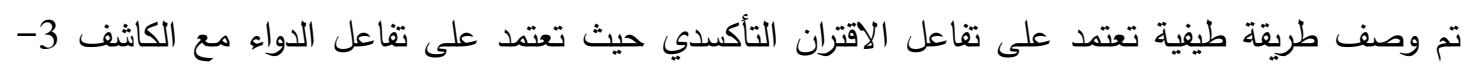

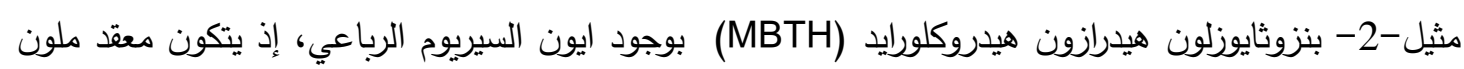

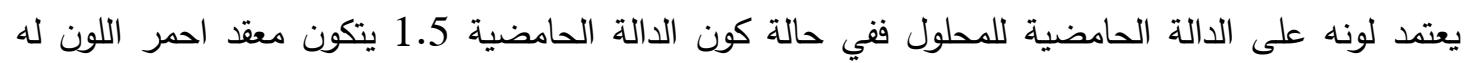
أقصى امتصاص عند 500 نانوميتر وفي حالة كون الدالة الحامضية للمحلول تساوي 4.5 يتكون معقد لونه بنفسي له أقصى امتصاص عند 580 نانوميتر (35). تم تطوير طريقة طيفية حركية تعتمد على متابعة تكون

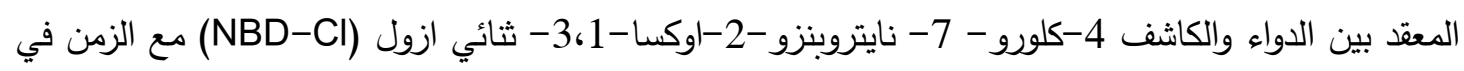

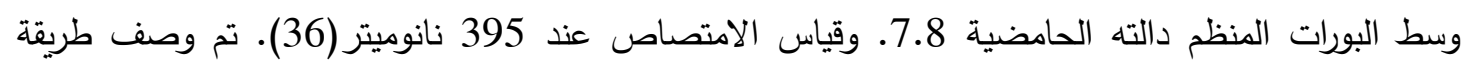
طيفية تعتمد على تكوين لون وردي من تفاعل الدواء مع4 - أمينو انتي بايرين وسط قاعدي وقياس اللون الون

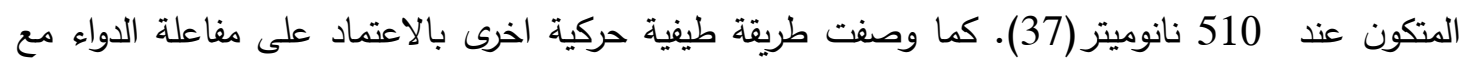
هيدروكسيل امين هيدروكلور بوجود ايون السيريوم الرباعي وقياس اللون الناتج عند 380 نانوميتر (38).تم فئن

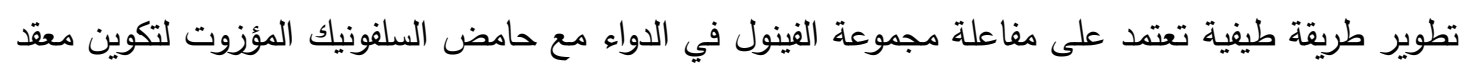
الدايزونيوم الذي له أقصى امتصاص عند 443 نانوميتر (39). 


\section{الجزء العملي}

\section{1-3-2 الأجهزة المستخدمة}

أجريت القياسات الطيفية باستخدام جهاز المطياف الفوتومتري ذي الحزمة المزدوجة نوع: Shimadzu UV-1650 PC UV-Visible-Spectrophotometer أجريت عمليات الوزن باستخدام ميزان حساس نوع AND GR-200، عمليات التسخين أجريت باستخدام حمام مائي نوع Forst Instrument LTD المواد والمحاليل الكيميائية المستخدمة

كانت جميع المواد الكيميائية المستخدمة والكواشف التحليلية على درجة عالية من النقاوة محلول الدايكلوفينك والأيزوكسبرين (100 مايكروغرام / مللتر) تم تحضير محلول 100 مايكروغرام/ مللتر وذلك بإذابة 0.01 غرام كل من الدايكلوفينك و والأيزوكسبرين

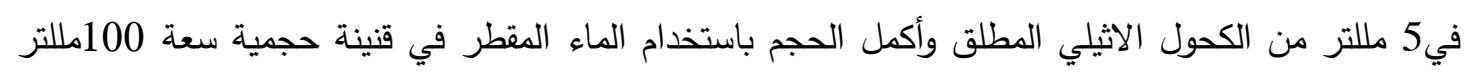
بعدها تم تحضير تراكيز مختلفة منه. محلول صبغة أخضر الملاكيت ( 200 مايكروغرام / مللتر) تم تحضير محلول 200 مايكروغرام/ مللتر وذلك بإذابة 0.02 غرام من ملح أخضر الملاكيت في الماء المقطر باستخدام قنينة حجمية سعة 100مللتر .

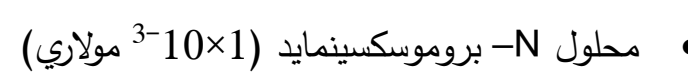
تم تحضير محلول العامل المؤكسد N- بروموسكسينمايد وذلك بإذابة 0.0449 غرام من المادة النقية في

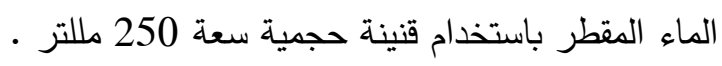
محلول حامض الهيدروكلوريك ( 0.1 مولاري)

تم تحضير حامض الهيدروكلوريك وذلك بتخفيف 25 مللتر من الحامض المركز باستخدام قنينة حجمية سعة

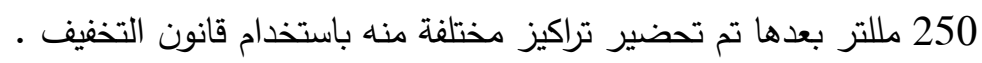
التقدير الطيفي للمركبات الاوائية الدايكلوفينك والأيزوكسبرين في المحلول المائي طريقة العمل

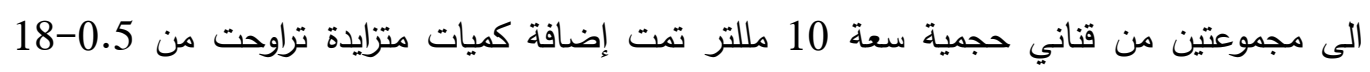

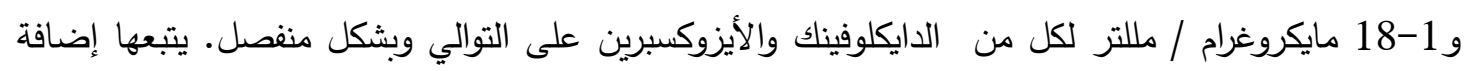
1 مللتر من 0.1 مولاري من حامض الهيدروكلوريك و 1.5 مللتر من العامل المؤكسد N-بروموسكسينمايد 


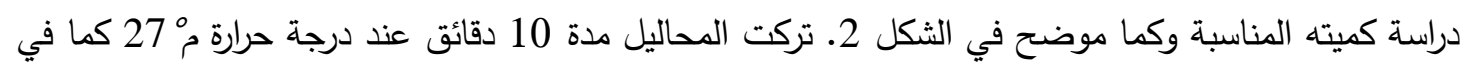
ملخص الظروف المثلى لإتمام عملية الأكسدة بعدها تم التخفيف بالماء المقطر وقياس امتصاص النواتج الملونة

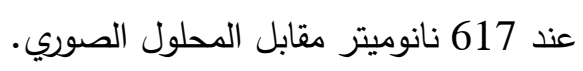

تحليل حقن الاولفين (الدايكلوفيناك)

تم تخفيف محتويات حقنة من الاولفين الحاوية على 75 ملغم/3 مللتر الايكلوفيناك في كمية من الماء

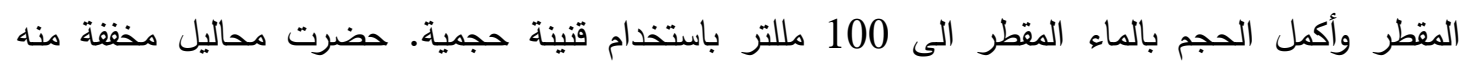
وعوملت وفق الطريقة المقترحة والموصوفة وتم إيجاد تركيز الدايكلوفيناك الموجود في الحقنة. تحليل حقن الدوفالين (الأيزوكسبرين) تم تخفيف محتويات حقنة واحدة من الدوفالين الحاوية على 10 ملغم /2 ملتر الأيزوكسبرين مع كمية من

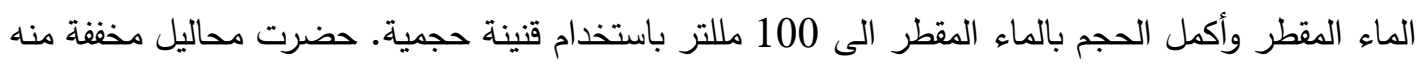
وعوملت طريقة العمل الموصوفة نفسها وتم إيجاد تركيز الايزوكسبرين الموجود في الحقنة.

تحليل أقراص كاتافلام (الدايكلوفيناك)

وزنت 5 أقراص من الانموذج الدوائي كاتافلام وبعد طحنها بدقة ومزجها جيدا ، وزن ما يعادل 0.320 غرام

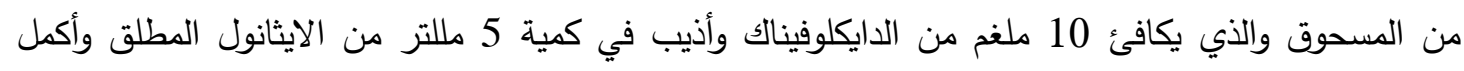

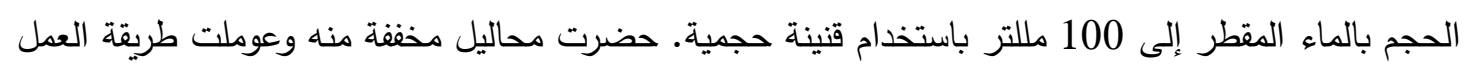
الموصوفة نفسها وتم إيجاد تركيز الدايكلوفيناك الموجود في القرص الدواءئي.

تحليل أقراص الدوفالين (الأيزوكسبرين)

وزنت 5 أقراص من الانموذج الدوائي الدوفالين وبعد طحنها ومزجها جيدا ،وزن ما يعادل 0.1966 غرام من المسحوق والذي يكافئ 10 ملغم من الايزوكسبرين وأذيب في كمية 5 مللتر من الايثانول المطلق وأكمل الحجم بالماء المقطر إلى100 ملتر باستخدام قنينة حجمية. وعوملت وفق طريقة العمل المقترحة والموصوفة وتم إيجاد تركيز الايزوكسبرين الموجود في القرص الدوائي.

تحليل مسحوق فول فولت فاست (الدايكلوفيناك)

تم وزن 3 أكياس من الانموذج الدوائي فولت فاست والموجود على شكل مسحوق ومزجت المحتويات مزجا

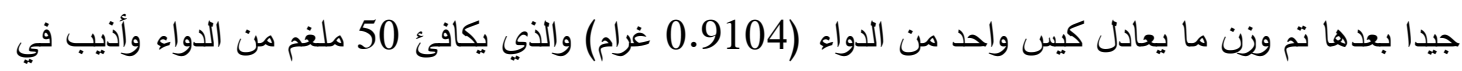

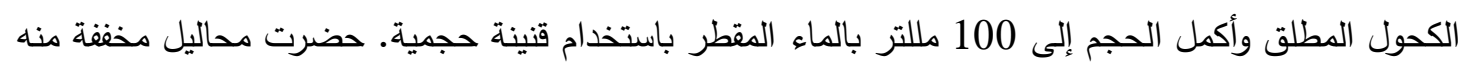
وعوملت طريقة العمل الموصوفة نفسها وتم إيجاد تركيز الدايكلوفيناك الموجود في الكيس الواحد. 


\section{النتائج والمناقثة}

طيف الامتصاص

يتأكسد كل من الدايكلوفيناك والأيزوكسبرين بواسطة زيادة معلومة من العامل المؤكسد N- بروموسكسينمايد

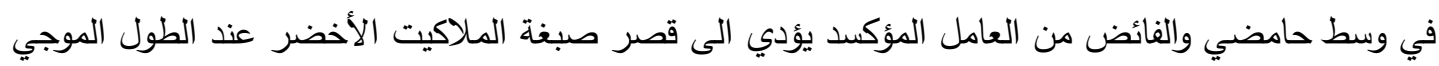

617 نانوميتر الثكل (1)

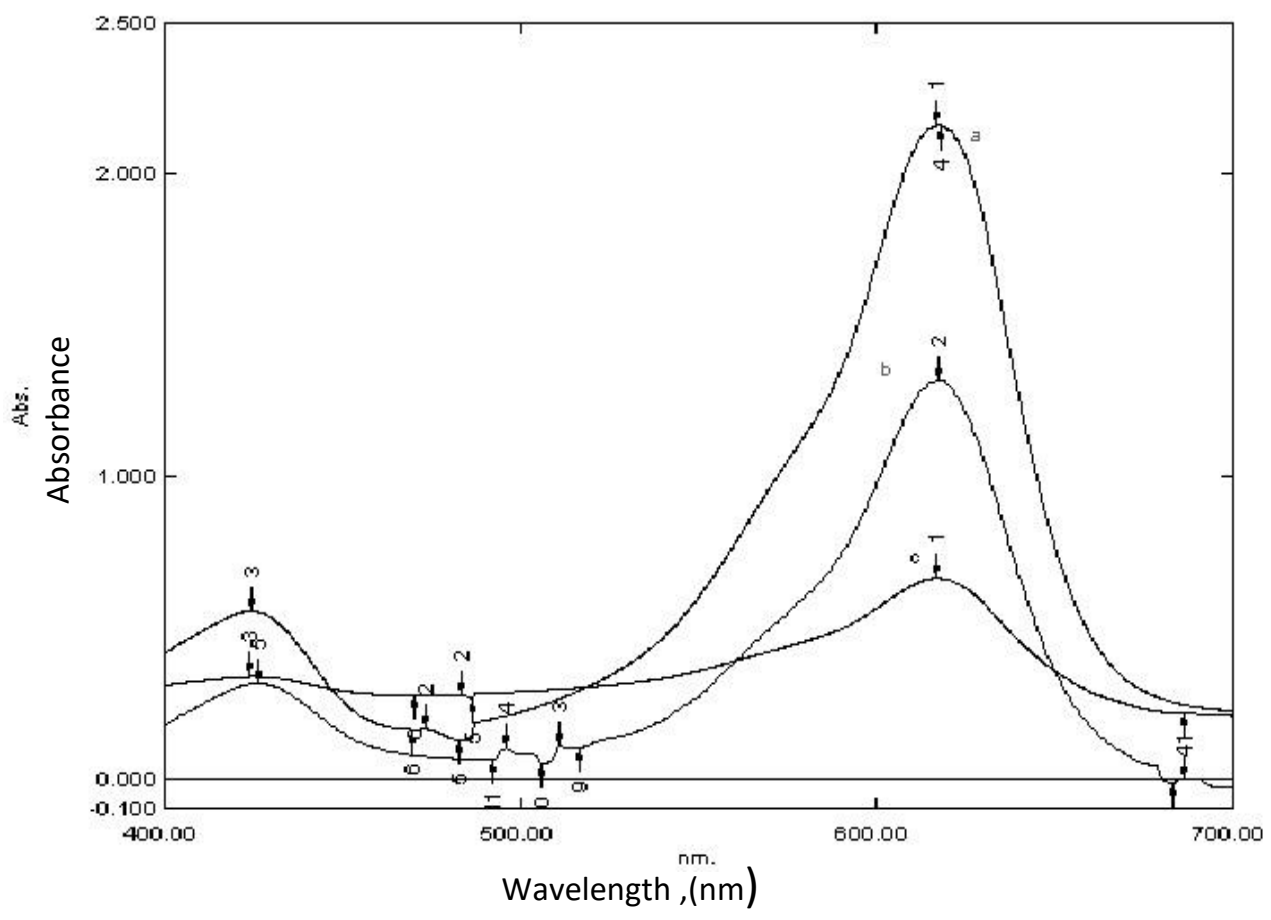

(1) الشكل)

$$
\begin{aligned}
& \text { (a) طيف امتصاص صبغة أخضر الملاكيت (8 مايكروغرام/مللتر) (a) } \\
& \text { (b) بوجود } 8 \text { مايكروغرام/ مللتر دايكلوفيناك (a) (b) }
\end{aligned}
$$

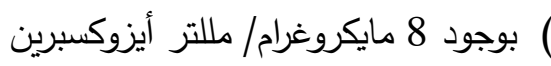

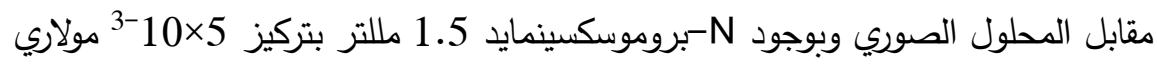

دراسة الظروف المثلى

تم دراسة الظروف المثلى لعملية الاكسدة وتقدير المركبات الدوائية قيد الدراسة من درجة الحرارة، الكميات المتفاعلة، الطول الموجي المناسب، وكمية العامل المؤكسد وصبغة الملاكيت الاخضر ودونت المبند النتائج في

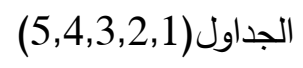


الجدول (1) الزمن اللازم لعملية أكسدة الصبغة

\begin{tabular}{|c|c|c|c|c|c|c|}
\hline Time (min) & 3 & 5 & 7 & 8 & 9 & 10 \\
\hline Absorbance & 1.62 & 1.12 & 0.96 & 0.33 & 0.08 & 0.00 \\
\hline
\end{tabular}

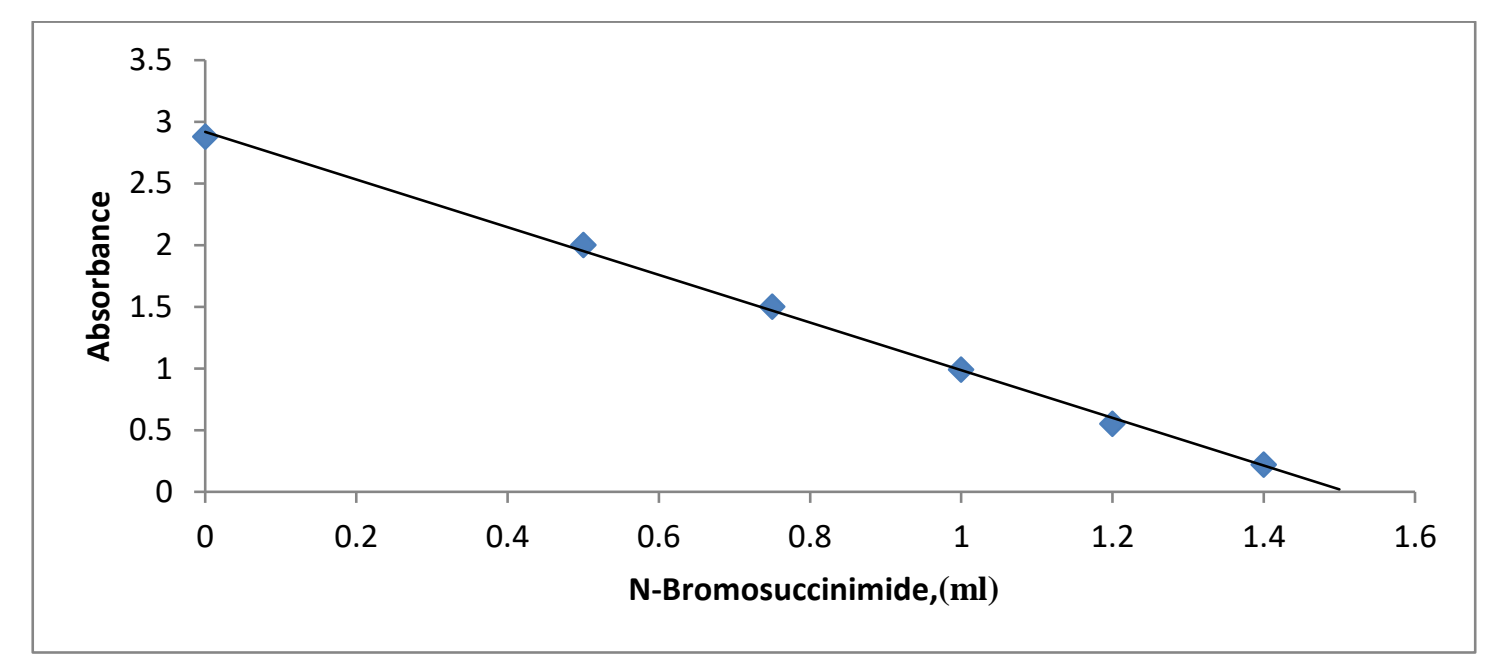

الثكل (2) تأثير كمية العامل المؤكسد على امتصاص صبغة أخضر الملاكيت.

الجدول(2) دراسة تأثير تركيز حامض الهيروكلوريك

\begin{tabular}{|r|c|c|c|c|c|}
\hline Molarity of HCl & 0.1 & 0.2 & 0.5 & 0.8 & 1 \\
\hline Absorbance & 2.88 & 2.88 & 2.78 & 2.78 & 2.63 \\
\hline
\end{tabular}

الجدول (3) دراسة تأثير كمية حامض الهيدركلوريك

\begin{tabular}{|c|c|c|c|c|c|c|c|}
\hline $\begin{array}{c}\text { Volume of 0.1 M } \\
\text { HCl(ml) }\end{array}$ & 0.5 & 1 & 1.5 & 2 & 3 & 4 & 5 \\
\hline Absorbance & 2.65 & 2.88 & 2.88 & 2.75 & 2.76 & 2.269 & 2.260 \\
\hline
\end{tabular}


الجدول (4) تأثير درجة الحرارة والزمن في امتصاص الصبغة وأستقراريتها بوجود8 مايكروغرام من الايكلوفيناك الكان

\begin{tabular}{|r|c|c|c|c|c|c|c|c|c|c|}
\hline $\begin{array}{r}\text { Time } \\
(\mathbf{m i n})\end{array}$ & \multirow{5}{*}{$\mathbf{5}$} & $\mathbf{8}$ & $\mathbf{1 0}$ & $\mathbf{1 2}$ & $\mathbf{1 4}$ & $\mathbf{1 5}$ & $\mathbf{2 0}$ & $\mathbf{3 0}$ & $\mathbf{4 5}$ & $\mathbf{6 0}$ \\
\cline { 1 - 11 } Temp c $^{\mathbf{0}}$ & & & & & & & & & & \\
\hline 10 & 1.10 & 1.14 & 1.18 & 1.15 & 1.21 & 1.26 & 1.29 & 1.35 & 1.40 & 1.40 \\
\hline 20 & 1.20 & 1.23 & 1.28 & 1.30 & 1.33 & 1.37 & 1.40 & 1.41 & 1.42 & 1.40 \\
\hline R.T & 1.26 & 1.39 & 1.43 & 1.43 & 1.42 & 1.44 & 1.42 & 1.40 & 1.41 & 1.40 \\
\hline 35 & 1.30 & 1.33 & 1.39 & 1.40 & 1.42 & 1.36 & 1.39 & 1.39 & 1.39 & 1.40 \\
\hline 40 & 1.40 & 1.41 & 1.42 & 1.37 & 1.36 & 1.33 & 1.30 & 1.27 & 1.25 & 1.20 \\
\hline
\end{tabular}

R.T $24-27^{\circ} \mathrm{C}$

الجدول(5) الظروف المثلى لتقدير المركبات الدوائية

\begin{tabular}{|l|l|}
\hline Condition & Result \\
\hline max & $617 \mathrm{~nm}$ \\
\hline Time & $10 \mathrm{~min}$ \\
\hline Temp & $27^{\circ} \mathrm{C}$ \\
\hline N-bromosuccinimide & $1.5 \mathrm{ml}$ \\
\hline Malachite green & $3.5 \mathrm{ml}$ \\
\hline Hydrochloric acid $0.1 \mathrm{M}$ & $1 \mathrm{ml}$ \\
\hline
\end{tabular}

المنحنى القياسي

بإتباع طريقة العمل الموصوفة سابقا تم رسم العلاقة بين الامتصاص وتركيز الدايكلوفيناك والأيزوكسبرين

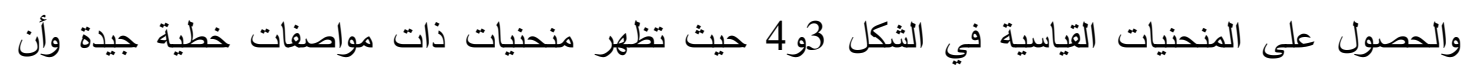

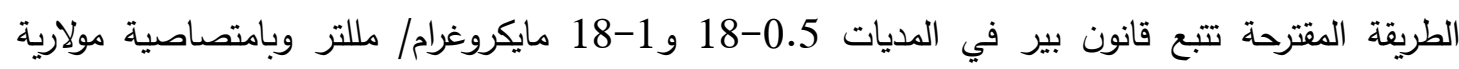

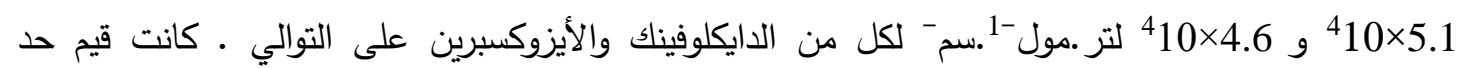

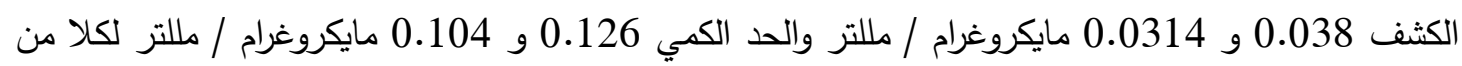
الدايكلوفيناك والأيزوكسبرين على التوالي. 


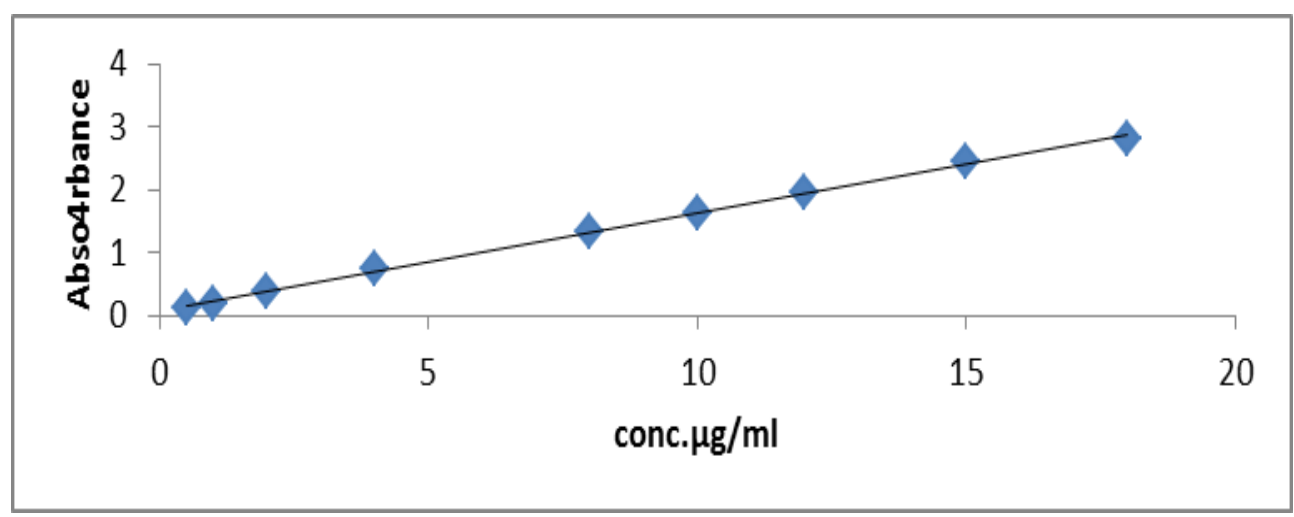

الشكل (4) المنحني القياسي لتقدير الايكلوفينك

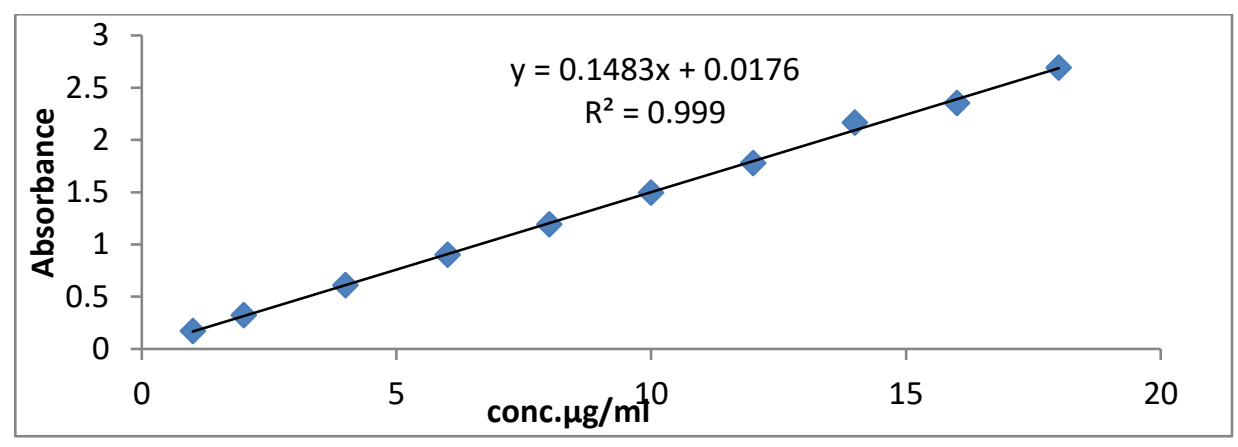

الثكل (5) المنحني القياسي لتقدير الأيزوكسبري

دقة الطريقة وتوافقها

تم فحص دقة الطريقة وتوافقها من خلال احتساب نسبة الاسترجاع والانحراف القياسي النسبي باستخدام

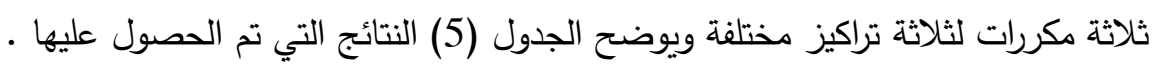
الجدول (6) دقة الطريقة وتوافقها

\begin{tabular}{|c|c|c|c|c|c|}
\hline Drug & $\begin{array}{c}\text { Amount of drug } \\
\text { added } \\
\boldsymbol{\mu g} / \mathbf{m l}\end{array}$ & $\begin{array}{c}\text { Found } \\
\boldsymbol{\mu g} / \mathbf{m l}\end{array}$ & $\begin{array}{c}\text { Recovery* } \\
\text { \% }\end{array}$ & $\begin{array}{c}\text { Average } \\
\text { of } \\
\text { Recovery } \\
\boldsymbol{\%}\end{array}$ & RSD $^{*}$ \\
\hline Dichlofenac & 4 & 4.09 & 102.25 & & 1.44 \\
& 8 & 8.07 & 100.87 & 101.20 & 1.19 \\
Isoxsuprine & 12 & 12.06 & 100.50 & 0.25 \\
\hline & 4 & 3.98 & 99.50 & & 1.72 \\
& 12 & 8.10 & 101.25 & 100.80 & 0.97 \\
\end{tabular}

*Average of recovery determinations 
ويشير الجدول (6) إلى أن الطريقة ذات دقة وتوافق جيدين إذ كانت قيم معدل نسبة الاسترجاع

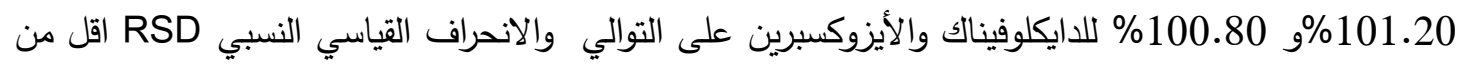

1.5

التطبيقات التحليلية

لقد طبقت الطريقة المقترحة بنجاح في تقدير الدايكلوفيناك والأيزوكسبرين في مستحضراته الصيدلانية

المتضدنة اقراص دوائية ومسحوق وحقن ودونت النتائج المستحصلة في الجدول(7).

الجدول (7) تقدير الدايكلوفيناك و الايزوكسبرين في مستحضراتهما الصيدلانية

\begin{tabular}{|c|c|c|c|c|}
\hline $\begin{array}{c}\text { Pharmaceutical } \\
\text { Preparation }\end{array}$ & $\begin{array}{c}\text { Certified } \\
\text { Value }\end{array}$ & $\begin{array}{c}\text { Amount } \\
\text { Added } \\
\mu \mathrm{g} / \mathrm{ml}\end{array}$ & $\begin{array}{l}\text { Drug content } \\
\text { found } \mu \mathrm{g} / \mathrm{ml}\end{array}$ & $\begin{array}{c}\text { Recovery } \\
\%\end{array}$ \\
\hline \multicolumn{5}{|l|}{ Diclofenac } \\
\hline \multirow{2}{*}{$\begin{array}{c}\text { Olfan } \\
\text { Injection }\end{array}$} & \multirow{2}{*}{$75 \mathrm{mg} / 3 \mathrm{ml}$} & 4 & 3.89 & 96.33 \\
\hline & & 8 & 8.16 & 102.66 \\
\hline \multirow{3}{*}{$\begin{array}{l}\text { Cataflam } \\
\text { Tablet } \\
\text { Novartis }\end{array}$} & \multirow{3}{*}{$10 \mathrm{mg}$} & 4 & 3.86 & 96.50 \\
\hline & & 8 & 8.19 & 102.37 \\
\hline & & 12 & 11.89 & 99.08 \\
\hline \multirow{3}{*}{$\begin{array}{l}\text { Voltfast } \\
\text { Powder } \\
\text { Novartis }\end{array}$} & \multirow{3}{*}{$50 \mathrm{mg}$} & 4 & 3.86 & 96.50 \\
\hline & & 8 & 7.82 & 99.97 \\
\hline & & 12 & 12.30 & 102.50 \\
\hline \multicolumn{5}{|l|}{ Isoxsuprine } \\
\hline \multirow{3}{*}{$\begin{array}{l}\text { Duvadilan } \\
\text { Injection } \\
\text { Zuzo pharm } \\
\text { Venczula }\end{array}$} & \multirow{3}{*}{$10 \mathrm{mg} / \mathrm{ml}$} & 4 & 4.09 & 102.25 \\
\hline & & 8 & 7.99 & 99.87 \\
\hline & & 12 & 12.10 & 100.83 \\
\hline \multirow{3}{*}{$\begin{array}{l}\text { Duvadilan } \\
\text { Tablet }\end{array}$} & \multirow{3}{*}{$10 \mathrm{mg}$} & 4 & 4.10 & 102.50 \\
\hline & & 8 & 8.06 & 100.75 \\
\hline & & 12 & 12.19 & 101.58 \\
\hline
\end{tabular}

تطبيق طريقة الاضافة القياسية على الطريقة المقترحة

من أجل أثبات كفاءة الطريقة المقترحة وخلوها من تداخلات المضافات فقد طبقت طريقة الإضافة القياسية

على النموذجين الدوائيين وذلك بسبب تعذر تطبيق الطريقة القياسية لكل من الدوائيين لاعتمادهما على تقنية كروماتوغرافيا السائل ذات الأداء العالي المثبتة في دستور الادوية البريطاني (40) والدستور الامريكي (41) ـ 


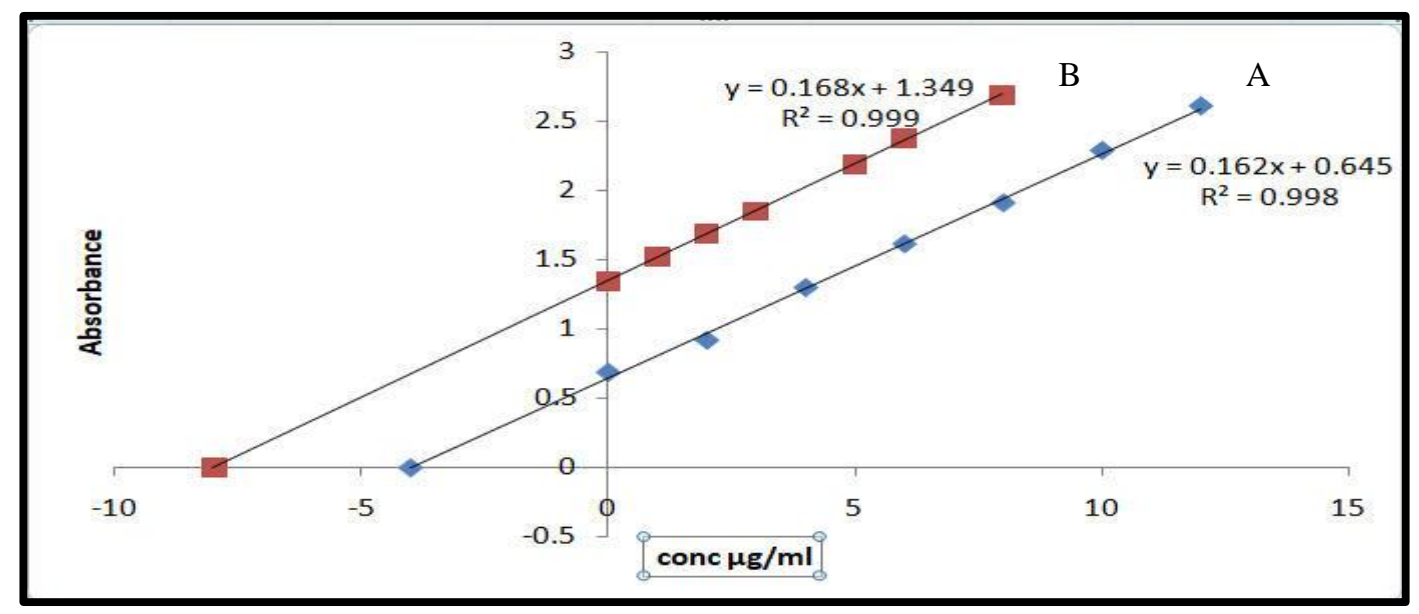

الثكل (5) منحني الإضافة القياسية لتقدير الدايكلوفيناك 4 (A) و8 (B) مايكروغرام/ مللتر

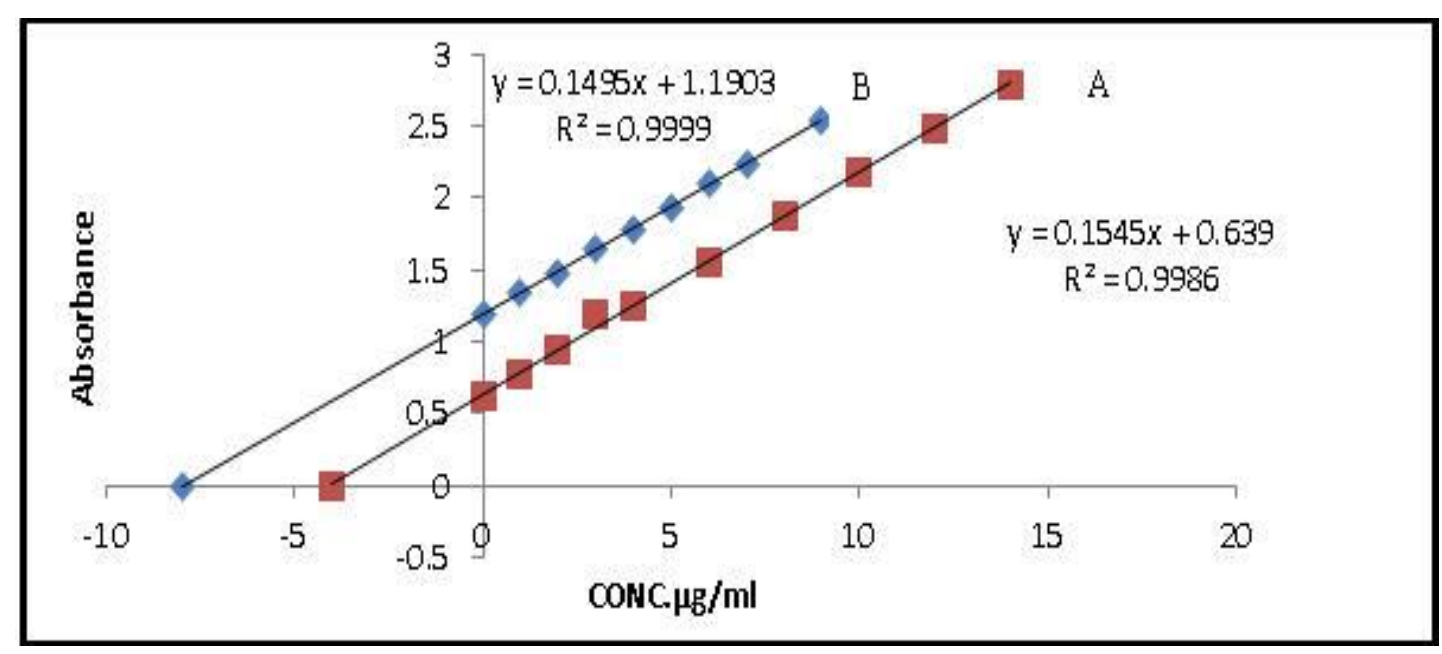

الشكل (6) منحني الإضافة القياسية لتقدير الايزوكسبرين 4 (A) و8(B) مايكروغرام/ مللتر

ومن ملاحظة النتائج المبينة في الثكل (5) و (6) والجدول (8) أن النتائج المستحصلة من طريقة الإضافة القياسية تدل على انتقائية الطريقة

الجدول (8) تقدير الدايكلوفيناك والأيزوكسبرين في المستحضرات الصيدلانية بطريقة الإضافة القياسية

\begin{tabular}{|c|c|c|c|}
\hline $\begin{array}{c}\text { pharmaceutical } \\
\text { preparation }\end{array}$ & $\begin{array}{c}\text { Amount } \\
\text { taken } \\
\boldsymbol{\mu g} / \mathbf{m l}\end{array}$ & $\begin{array}{c}\text { Amount } \\
\text { found } \\
\boldsymbol{\mu g} / \mathbf{m l}\end{array}$ & $\begin{array}{c}\text { Recovery } \\
\mathbf{\%}\end{array}$ \\
\hline Dichlofenac & 4 & 3.952 & 98.8 \\
\hline Isoxsuprine & 8 & 7.965 & 99.56 \\
\hline
\end{tabular}




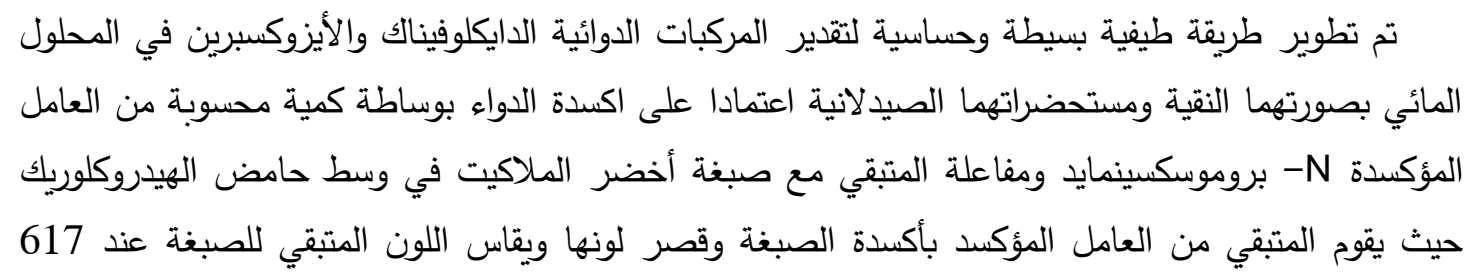

امكن تطبيق الطريقة بنجاح في تقدير الدايكلوفيناك والأيزوكسبرين في مستحضراته الصيدلانية المتضمن حقن ومسحوق وحبوب ، وكانت النتائج متفقة على نحو جيد مع المحتوى الاصيل للمستحضرات الصيدلانية وكذلك مع طريقة الاضافة القياسية .

\section{المصادر}

1- Hakam Al-Zaam. Drugs science. Lippincott's llustraled Reviews $4^{\text {th }}$ edition Richard A. Harvey, Pamela C. champe pharmacology (2008).

2- Grahaml Patrick, "An Introduction to Medicinal chemistry", $5^{\text {th }}$ Ed. oxford united kindom, printed in Italy by L.E.G.O.S.P.A.- Lavis, (2009).

3- Gareth Thomas," fundamentals of Medicinal chemistry" university of Portsmouth, uk. John Wiley and son limited (2003).

4- Cole. C. Bentz, and B. Maxwell,"Clinical pharmacology of the equine musclosk etetal system", Equine pharmacology, wiley-Blackwell pp. 224 (2014).

5- F. Giorgin, C. Egen, "Use of isoxsuprine hydrochloride as tocolotic agent in the treatment of pretem labour", Asystematic review of previous literature Arzneimite- Forachung, 60, 7, pp. 415-420 (2010).

6- Http://www. Nobi. nim ningov./pmo/ article, PMC3422823.

7- N. Rahman, S. Lotfi, Iraq National Journal of chemistry, vol.44, pp. 467-473 (2011).

8- R .Kasperek, Acta poloniae pharmaceutical Drug research, vol.65, No.4, pp. 403408 (2008).

9- B .Yilmaz, A. Asci and S. palaliyik, Journal of chromatographic science, Vol. 49, pp. 422-427 (2011).

10- B. Gowramma, S. Rajan, S. Muralid haran and B. suresh, International Journal of chem. Tech. Research, vol. 2, No.1, pp. 676-680 (2010).

11- U. Ciltas, B. Yilmaz, B. Kaan and G. Nazik, Indian Journal of pharmaceutical research, 14,3, pp. 715-722 (2015).

12- I. Saliah, J. Baker and S. Alshraf, Journal list. Chem. Cent. Vol.10 (2016).

13- E.G. Ciapina, A.O. Santini, H.R. Pezza and L. pezza, "Spectrophotometric deter mination of diclofenac in pharmaceutical pre parathion assisted by microwave oven". Ecletica Quimica, vol.30, (1), pp. 29-36 (2005).

14- B.V. Kamath, K. shivram and A. shah, Journal of pharmaceutical and biomedical analysis, vol. 12, issue 3, pp. 343-346 (1994).

15- A.. Raza, T. Nasri and S. Niazi, pak. J. Anal. Chem. Vol.6, No.1, pp. 5-9 (2005). 
16- A.M. Mahmood and M.J. Hamezh, Journal of Karbala university, vol.7, No.2 (2009).

17- S.B.Dikran, R.M.Mahmood, Ibn Al- Haithm Journal for pure and appl. sci, vol. 28, (3), p.129 (2017).

18- R.L. Souza, M. Tubino, J. Braz. Chem. Soc., vol.16,5 (2005).

19- Q N. Rashid, M.H. Bakir and S.O. Baban, Tikrit Jouranal of pure science, 21, (3), pp. 76-80 (2016).

20- Y.K.Agrawal,K.ShivrramchandraJournal of pharmaceutical and Biomedical Analysis, vol. 9, issue 2, pp. 97-100(1991).

21- M.A. Castillo and L. Bruzzone, Analytical science vol.22, pp. 431-433(2006).

22- G. Pandey, international Journal of bio medical and advance research, 4,2, pp. 77 80 (2013) .

23- O.S. Idowu, O. Adegoke, B. Oderinu and A. Olainy, pak. J. pharm, SCI. Vol.19(2), pp. 141-147 (2006) .

24- B.U. Ebeshi, V.N. Edebi and O. Assuai, international Journal of Bioassays, 03, (01), pp. 1647-1652 (2014).

25- N. W. Beyene, J. Vanstaden and H. Y. Aboul - Eein, Farmaco Societa chimica ltalaiana, Vol.60, ISSN 0014-827, pp. 613-619 (2006).

26- A. M. Sekar, A. Suresh and V. Niriamathi, Iint. J. pharm. Sci Rev. Res.,20, 2,PP. 170-172 (2013).

27- D. Sherbing, M. Ebdel. Gaffar and R, El-wassef, Jounl of liquid chromatography and related technologies, vol.33, lssue15, pp. 1476-1456 (2010).

28- K. Basavaiah. K. Tharpa and K. Vinay, Croact. Chem. Acta, 83,4,pp. 415-410 (2010).

29- P.Saritha, T. charan and C. Cyanakumari, IOSR journal of Applied chemistry", vol.8, Issue 8, pp. 43-49 (2015).

30- N.A. Alarfaj, Journal of pharmaceutical and biomedical analysis, vol.28, issue 2, pp. 331-335 (2002).

31- R.T. Sane, V. Nayak and V. Malkar, Talanta, vol.32, lssue1, pp. 31-33 (1985).

32- R.S. Bakry, A. Fattahand and S. Belal, Analytical letter, Vol.28, llissue 14 (1995).

33- H.D. Revanas lddapa, M.A. Veena,E. Journal of chemistry Vol. 5, No.1,pp. 100106 (2008).

34- K. Basaviah, K. Tharpa and K. Vinay, Using Folin- Ciocaltens reagent, proc. Indian Nath sci Acad, 76, 3, pp.149-156 (2010).

35- K. Tharpa, K. Basavaiah, K. kanakapure and B. vinay, Talanta. Vol.81, issue 4-2, pp.1216-1223 (2010).

36- N. El-Enany ,F. Belal and M. Rizk, 74, pp. 99-119 (2006).

37- D. Hosokere, B. Gowda, Journal of AOAC international, vol.83, No.6, pp. 14401445 (2000).

38- N. Rahman. N. Afaq, Drug testing and Analysis, Vol.2, issue 9 (2010) .

39- A. Daly, P. Mishra and K. Jain, Indian Journal, vol. , issue 2, pp. $82-85$ (2007).

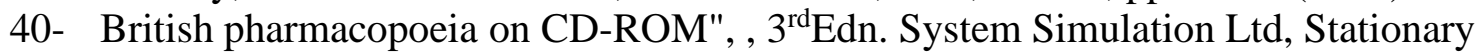
Office London (2000).

41- "United State Pharmacopoeia", The National Formulary United State Pharmacopoeia Convention, INC, 12601,Twin Book Parkway, Rockville, MD (1995). 